\title{
Glutathione disulfide as an index of oxidative stress during postischemic reperfusion in isolated rat hearts
}

\author{
Robert J.A.M. Verbunt, Willem G. van Dockum, E.M. Lars Bastiaanse, \\ Janneke M. Egas and Arnoud van der Laarse \\ Department of Cardiology, University Hospital Leiden, Leiden, The Netherlands
}

The authors of the above-mentioned article (Molecular and Cellular Biochemistry 144: 85-93, 1995) wish to correct Figure 1 of the article. The error introduced by incorrect calculation of tissue GSSG concentration in one group of hearts has no implications for the text, nor for the conclusions that were drawn from the results obtained. Please find below the corrected Fig. 1:

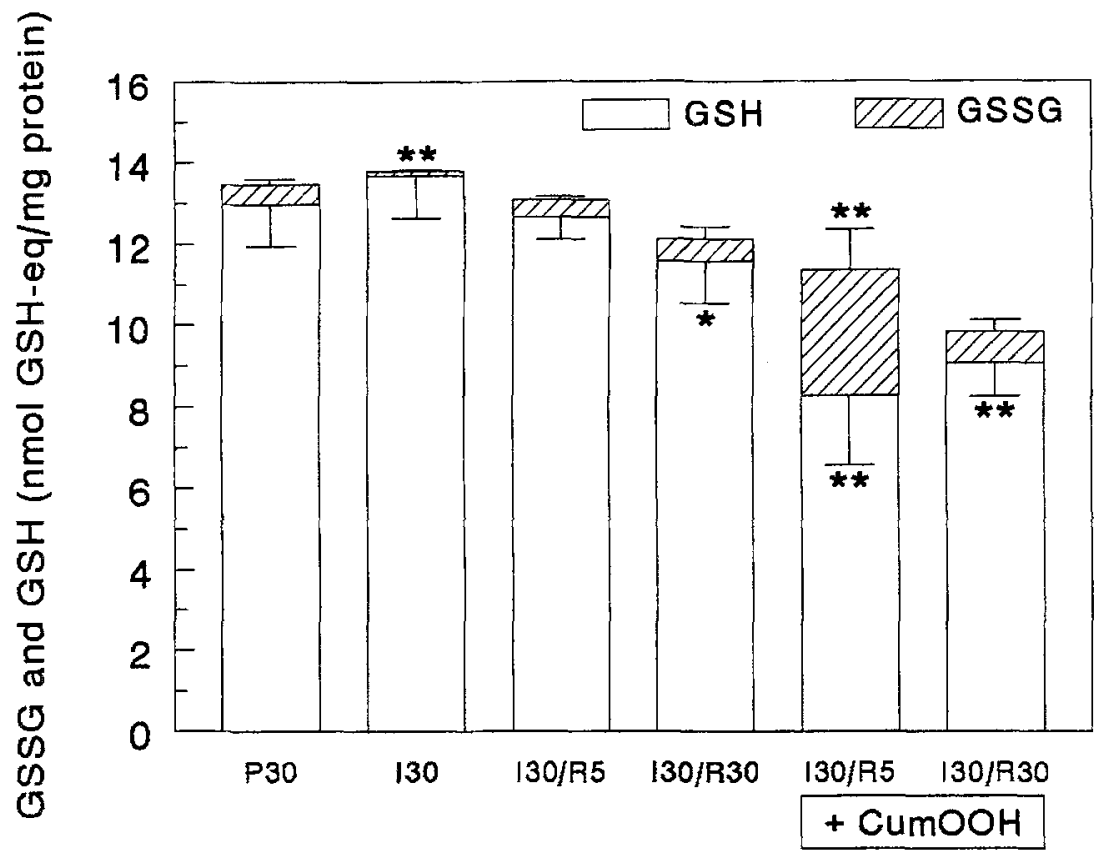

Fig. 1. Myocardial contents of GSSG and GSH during postischemic reperfusion with or without administration of cumene hydroperoxide. Isolated rat hearts were subjected to $30 \mathrm{~min}$ of non-ischemic control perfusion (P30), to $30 \mathrm{~min}$ of hypothermic no-flow ischemia (I30), and to $30 \mathrm{~min}$ of hypothermic ischemia followed by 5 or $30 \mathrm{~min}$ of reperfusion (130/R5 and I30/R30, respectively). Cumene hydroperoxide (CumOOH, $20 \mu \mathrm{M})$ was administered at the onset of reperfusion either for $5 \mathrm{~min}$ (these hearts were reperfused for only $5 \mathrm{~min}$ ) (I30/R $5+\mathrm{CumOOH}$ ), or during the first $10 \mathrm{~min}$ of $30 \mathrm{~min}$ of reperfusion (I30/R30-CumOOH). Data represent means \pm SD for 5-7 hearts. ${ }^{*} p<0.05,{ }^{* *} p<0.01$ vs. P30. 